International Journal of Wireless \& Mobile Networks (IJWMN) Vol. 3, No. 5, October 2011

\title{
AN ENHANCED SINR-BASED CALL ADMISSION CONTROL IN 3G NETWORKS
}

\author{
Moses Ekpenyong ${ }^{1}$ and Joseph Isabona ${ }^{2}$ \\ ${ }^{1}$ Department of Computer Science, University of Uyo, Nigeria \\ ekpenyong_moses@yahoo.com \\ ${ }^{2}$ Department of Basic Sciences, Benson Idahosa University, Benin City, Nigeria \\ josabonedyahoo.com
}

\begin{abstract}
This paper presents the signal-to-interference plus noise ratio (SINR)-based call admission control $(C A C)$ as an effective technique that guarantees signal quality for admitted users. We propose a CAC model that admits users as long as the SINR exceeds a threshold $\left(S I N R_{t h}\right)$. To reduce blocking, we ensure that the threshold level is maintained at a lower bound $\left(S I N R_{l b-t h}\right)$, convenient to keep the blocking probability $\left(P_{b}\right)$ below a maximum value $\left(P_{b-\max }\right)$. We simulate the CAC model with the Java programming language and evaluate the performance of the model. Simulation results show that our CAC scheme produce the expected performance that improves the network quality.
\end{abstract}

\section{Keywords}

Blocking probability, SINR threshold, QoS, outage probability

\section{INTRODUCTION}

Recent advances in wireless networks and mobile devices design are inclined towards the emergence of ubiquitous computing, comfortable for application users running on mobile terminals (MT) to enjoy seamless roaming. It is well known that the basic problem in wireless networks is the scarce radio resources. This problem therefore demands efficient radio resource management. Call admission control (CAC) is one of the radio resource management techniques that play a dominant role in the effective management of radio resources. It can be defined as a provisioning strategy that limits the number of call connections in a network and aims at mitigating network congestion and call dropping [1].

The admission control in wireless networks will reduce the call blocking probability by optimizing the utilization of available radio resources. The mobile communication environment is featured by moving terminals with different Quality of Service (QoS) requirements and in this current scenario, the need for guaranteed QoS is more sought for.

In Code Division Multiple Access (CDMA), radio resources are also scarce quantities [2]. Each user is assigned a code which is spread out to the available frequency. The assigned code is expected to be orthogonal to other users' codes. As the number of users increases, interference between users also increases, and causes a deterioration of the desired QoS. Hence, a standard 
International Journal of Wireless \& Mobile Networks (IJWMN) Vol. 3, No. 5, October 2011

should be maintained for providing good service quality to the users. This standard is referred to as the Quality of Service (QoS). Call Admission Control (CAC) constitutes one of the numerous techniques for radio resource management of wideband CDMA. Given the increasing throughput demands upon the uplink channels, uplink admission control has become more important an issue. Previous cellular traffic used predominant constant bit rate voice calls, but with the addition of new services, the uplink channels in recent times are becoming more "bursty" with long-tailed traffic [3]. With high demands for cellular systems to accommodate large number of users, micro and pico cellular structures have emerged [4]. These demands result in handoff, because different cells must cooperatively service the users in an efficient manner. Other performance measures are throughput, blocking probabilities of new calls, handoff calls and system resource utilization. These problems have necessitated this paper, which provides an appropriate base for the examination of SINR-based CAC and improves the QoS in $3 \mathrm{G}$ networks.

Designing call admission control algorithms for mobile cellular networks has posed great challenges given the limited and highly variable resources, and users' mobility in such networks. An admission control mechanism accepts a new call request provided there are adequate free resources available to meet the QoS requirements of this request, without violating the committed QoS of already accepted calls. This condition imposes additional tradeoff between the QoS level perceived by the user and the utilization of scarce wireless resources. Precisely, CAC can be described as an optimization problem [5].

Call admission algorithms are required to provide resources for guaranteed real-time services, such as voice calls. When a user requests resources, the admission control algorithm should verify that the request can be met by checking the loading cell of the available WCDMA transmission resources. If there are available resources, the Radio Network Controller (RNC) will allocate and reserve them, then update the load control and finally admit the user. It is at this point that the RNC decides what type of channel to allocate a user. If the resource(s) is(are) not available, the RNC either rejects the request or makes a counter offer of resources that are available. The admission control is designed to meet a planned load level and place a reasonable safety margin below the maximum resources available. A typical range is $50 \%$ to $70 \%$ of planned load [6].

Before a call is established, the network decides whether there are enough resources available for the connection. Otherwise, either the call is queued, offered a lower quality of service or rejected entirely. The RNC has to consider the effect on other users within the cell and possibly within adjacent cells if the call proceeds. Within the WCDMA system, each connection shares the same spectrum simultaneously as other users, and users are permitted connection in a cell. They also cause interference for other users in same cell and for other users in adjacent cells, since the frequency reuse is unity. This implies that adjacent cells share same frequency. A user transmitting at a high data rate introduces a higher quantity of wideband noise than a user who simply makes a voice call. The network has to determine beforehand what data rate a user requires and estimate how much noise will be generated in that cell. If the noise value is very high, too much interference for other users in the cell will occur and their call quality will be reduced. It is also important for CAC algorithms to take into account the load on surrounding cells. This is to ensure that users who migrate from cell to cell do not lose their connections. In this paper, an efficient SINR-based CAC model that enhances wireless networks performance and reduce blocking probability is proposed. 
International Journal of Wireless \& Mobile Networks (IJWMN) Vol. 3, No. 5, October 2011

The paper however proceeds with a review of related works on CAC, proposes the system's model, followed by a simulation of the model under ideal conditions/environment and finally discusses the simulated results.

\section{REVIEW OF RELATED WORKS}

Several SINR-based CAC schemes that use SINR as call admission criterion have been extensively studied in literature as an efficient technique for managing radio resources in wireless networks [7-12]. In [7,8], an optimal call admission design for maximizing the network capacity (minimizing the blocking probability) is studied. The optimal call admission problem is formulated as a semi-Markov decision process (SMDP) with constraints on blocking probabilities and signal-to-interference ratio (SIR). They show that the optimal admission policy can be determined via a linear programming-based algorithm, and the network capacity can be further increased if users requesting connections are queued when resources are not available. However, the approach in [7] optimizes only the network layer performance, whereas the powers at the physical layer are poorly chosen.

In [13], an SINR model that maximizes the capacity of arbitrary wireless networks is proposed. They show that if the received SINR is less than the threshold, calls are rejected. In order to accommodate large number of mobile users, cells (area covered by one base station) have micro and pico cellular structure to facilitate users movements from one cell to another. This requires handing over of ongoing calls from one cell to another, a situation called 'handoff'.

Estimates of the lowest SIR level in the home cell and adjacent cells, in addition to the estimates of the short term and long-term outage probability $\left(P_{\text {out }}\right)$, are employed in [14] for call admission in WCDMA. They assume multi-user detection for estimating the SIR. A fuzzy logic-based scheme decides to admit incoming calls based on the estimated values of SIR and $P_{\text {out }}$. Their results show that the proposed scheme outperforms conventional SIR-based CAC in terms of system capacity and outage probability. An integrated SIR-based resource management scheme that encompasses CAC, handoff, power control (PC), and dynamic channel allocation (DCA) has been proposed in [15]. The CAC scheme simply compares the achievable SIR of the new user with a threshold value $S I R_{\text {new }}$ and admits new users as long as $S I R>S_{n e w}$. Their CAC scheme is similar to the algorithm proposed in [9]. An SIR-based CAC has been proposed in [16] for indoor wireless multimedia systems. In their algorithm, different threshold values of SIR are used for each class of traffic depending on the required Bit Error Rate (BER), taking into account the BER due to packet loss of overflowed buffers in the fixed network. The impact of SIR-based schemes on the spatial distribution of blocking probability $\left(P_{b}\right)$ in WCDMA has been analyzed in [17]. They show that in a hexagonal cell structure $P_{b}$ increases from 1.5 percent to 3 percent as the distance between the MS and the BS increases from $0.1 \mathrm{~km}$ to $0.5 \mathrm{~km}$. A further increase in the distance does not produce any significant change in $P_{b}$. However, in a realistic network environment, $P_{b}$ has larger spatial variation. It has been found that $P_{b}$ can be as high as 50 percent at the cell border even if it is less than 5 percent in the middle of the cell. In [18], the authors concentrate on SIR-based CAC scheme for hybrid T/CDMA (TDMA and CDMA) systems supporting both voice and data services. Two different approaches are used in this work. The first approach uses multicode T/CDMA allocation for data users, while the second approach implements multislot T/CDMA allocation for data users. Voice users are assigned a single code and a single slot in both 
International Journal of Wireless \& Mobile Networks (IJWMN) Vol. 3, No. 5, October 2011

approaches. In the first approach, the call is admitted if there is at least one time slot with $R$ codes that meets the SIR condition (minimum SIR can be achieved for a new user as well as existing users), where $R$ is the ratio of the transmission rate of data users to that of voice users. On the other hand, in the second approach the SIR condition must be satisfied in all $R$ time slots with only one code per slot. It is worth noting that it is irrelevant to assign same code in the $R$ time slots. It has been shown that multicode T/CDMA outperforms multislot T/CDMA in terms of system capacity, and also allows a tradeoff between the system capacity and the transmission rate. CAC in multicode CDMA is also investigated in [19]. The proposed scheme orders users based on their required $E_{b} / N_{0}$. Users are activated starting from the user with the lowest $E_{b} / N_{0}$. Before admitting a user, the CAC scheme checks whether the user can be assigned a minimum number of codes (corresponding to the minimum transmission rate). If the minimum number of codes can be assigned without violating the constraints on $E_{b} / N_{0}$, the user is admitted. Next, additional sequential assignment of codes are attempted to be assigned (in sequence) to the user to increase the transmission rate up to the maximum designated rate of the user. Then the system proceeds to the next user (next higher $E_{b} / N_{0}$ ) until all users are checked, such that every user is either admitted and allocated multiple codes or rejected due to system infeasibility.

Instead of using SIR as a criterion for call admission, the CAC scheme proposed in [20] employs the estimated outage probability $(\operatorname{Pr}(\operatorname{SIR}<$ SIRmin $))$ as a criterion for call admission. The outage probability of each class is estimated based on the number of users in each class and the power allocated to each active user. The outage probability assumes imperfect power control, which renders the SIR distribution log-normal. The new call is admitted only if the outage probability of each class is below the corresponding required level. Interference-based CAC schemes use the interference level as an admission criterion to guarantee the signal quality in terms of SIR.

A joint-optimal power and admission control for delay sensitive traffic in CDMA networks with LMMSE receivers is proposed in [21]. Here, QoS requirements are specified in terms of the target SIR requirement, and optimal target powers are dynamically adjusted according to the current number of users in the system. In [22], the cross-layer quality-of-service (QoS) provisioning in the uplink of CDMA cellular mobile networks is addressed. The QoS attributes are formulated based on the signal-to-interference-plus-noise ratio (SINR) and outage probability at the data link layer, as well as the average delay and packet loss rate at the network layer.

In this paper, we present a lower bound $\operatorname{SINR}_{t h}\left(\operatorname{SINR}_{t h-l b}\right)$-based call admission control (CAC) as an effective technique that guarantees signal quality for admitted users in CDMA networks under imperfect power control conditions. The proposed CAC scheme mimics a reallife case and is studied via an extensive simulation platform.

\section{SYSTEM MODEL}

In SINR-based CAC schemes, SINR of the reverse link is measured and then compared with a predefined threshold value $S I N R_{t h}$. The incoming call is admitted only if the measured SINR is above the threshold value $\left(\operatorname{SINR}_{t h}\right)$. In [9], the only constraint imposed on the SINR threshold value $\left(S I N R_{t h}\right)$ is the condition: $S I N R_{t h}>S I N R_{\min }$, where $S I N R_{\min }$ is the minimum SINR level for acceptable signal quality. Setting a high value for $S I N R_{t h}$ maintains the signal quality but increases the blocking probability $\left(P_{b}\right)$ and reduces network utilization. 
International Journal of Wireless \& Mobile Networks (IJWMN) Vol. 3, No. 5, October 2011

On the other hand, better resource utilization is achieve by lowering $\operatorname{SINR}_{t h}$. However, a small $S_{I N R_{\text {th }}}$ value allows more users to be admitted and might render power control (PC) feasible if the number of admitted users per cell exceeds a certain limit. If PC turns out to be infeasible, then the outage probability $\left(P_{\text {out }}=P\left(\operatorname{SINR}<S I N R_{\text {min }}\right)\right)$ increases, since SINR converges to a smaller level than the target value $\left(S I N R_{t r g}\right)$. Outage might also occur if power control is feasible due to SINR fluctuation [10] around the target value.

An upper bound of $\operatorname{SINR}_{t h}\left(\operatorname{SINR}_{t h-u b}\right)$ in a single class CDMA network has been derived in [11], such that $P_{\text {out }}$ can be kept below a maximum value. The upper bound of SINR $R_{\text {th }}$ $\left(S_{I N R_{t h-u b}}\right)$ in multi-class CDMA networks is derived in [12], such that the outage probabilities of all classes are kept below specified values. A lower bound of $\operatorname{SINR}_{\text {th }}$ ( $\left.S I N R_{t h-l b}\right)$ that keeps $P_{\text {out }}$ below a maximum value $\left(P_{\text {out }-\max }\right)$, has also been obtained for single class CDMA [10]. Similarly, we can define $\operatorname{SINR}_{t h}$ as the lowest value of SINR that keeps blocking probability $P_{b}$ below the maximum acceptable value of $P_{b}\left(P_{b \text {-max }}\right)$. Because outage and blocking are directly related, we apply the law of total probability, and $P_{b}$ can be related to $P_{\text {out }}$ as:

$$
P_{b}=\sum_{N=1}^{\infty} P_{o u t \mid N} P(N)
$$

where $P_{o u t N}$ represents the conditional outage probability and $P(N)$ is the probability that there are $N$ admitted users per cell. When imperfect PC is considered, SINR is modelled as a log-normally distributed random process. Hence, $P_{b \mid N}$ becomes:

$$
P_{b \mid N}=1-Q\left(\frac{S I N R_{\min }^{d B}-m}{\sigma}\right)
$$

where $m$ and $\sigma$ are the mean and standard deviation of $\operatorname{SINR}^{d B}$ respectively. Specifically, $\sigma$ is a constant that depends only on the delay and the PC errors. If PC is feasible, $m$ converges to the target value $\left(\operatorname{SINR}_{\operatorname{trg}}^{d B}\right)$, else $m$ starts to degrade and its value becomes a function of the number of active users $(\mathrm{N})$. Hence, $m$ can be represented as

$$
m=\left\{\begin{array}{l}
\operatorname{SINR}_{t r g}^{d B} N \leq N_{\text {max }} \\
10 \log _{10}\left(\frac{1}{(N-1)(1+f)+\left(\eta_{o} W / S\right)}\right) N>N_{\max }
\end{array}\right.
$$

where

$N_{\max }$ is the maximum number of admitted users for feasible power control

$\eta_{o}$ is the noise power spectral density 
International Journal of Wireless \& Mobile Networks (IJWMN) Vol. 3, No. 5, October 2011

$S$ is the targeted received power level

$W$ is the spreading bandwidth

$f$ is the ratio of the inter-cell interference to the intra-cell interference.

In fact, $N_{\max }$ is a function of the target $\operatorname{SINR}\left(\operatorname{SINR}_{t r g}\right)$ and can be shown to be equal to

$$
N_{\text {max }}=\left[\left(\frac{1}{\operatorname{SINR}_{\operatorname{trg}}}-\frac{\eta_{o} W}{S}\right) \frac{1}{(1+f)}+1\right]
$$

where $N_{\max }=[\xi]$ is the largest integer less than or equal to $\xi . P(N)$. This value has been determined in [10] by assuming that $N$ follows Poisson distribution. However, this assumption is found to be inaccurate since the arrival rate is not constant and depends on the blocking rate $\left(P_{b \mid N}\right)$, which in turn depends on the number of users, $N$.

Instead, $P(N)$ is determined here using the markovian (birth-death) model [23]:

$$
P(N)=\frac{\Lambda^{N}{ }_{i=1}^{N}\left(1-P_{b \mid N}\right)}{\sum_{i=o}^{\infty} \Lambda^{i}\left(\stackrel{i}{i=1}_{i=1}^{\pi}\left(1-P_{b \mid N}\right)\right)}
$$

where $\Lambda$ is the average traffic intensity in Erlang per cell, which is equal to $\frac{\lambda}{v}$, where $\lambda$ is the average arrival rate, while $\frac{1}{v}$ is the average call resident time. The conditional blocking rate $\left(P_{b \mid N}\right)$ is equal to the probability of $\left(\operatorname{SINR}^{d B} \leq \operatorname{SINR}_{t h}^{d B}\right)$. For $N$ users, $P_{b \mid N}$ is defined as in equation (2). From equations (1), (2) and (4), it is possible to express $P_{b}$ as a function of $\operatorname{SINR}_{t h}^{d B}$, i.e.,

$$
P_{b}=\sum_{N=1}^{\infty}\left\{\left(1-Q\left(\frac{\operatorname{SINR}_{\min }^{d B}-m}{\sigma}\right)\right) \frac{\Lambda^{N} \prod_{i=1}^{N} Q\left(\frac{\operatorname{SINR}_{t h}^{d B}-m}{\sigma}\right)}{\sum_{i=1}^{\infty} \Lambda^{i}\left(\prod_{j=1}^{i} Q\left(\frac{\operatorname{SINR}_{t h}^{d B}-m}{\sigma}\right)\right)}\right\}
$$

Therefore, $S I N R_{t h-l b}^{d B}$ can be obtained from equation (6) by equating $P_{b}$ to $P_{b-\max }$ and then solving for $\operatorname{SINR}_{t h-l b}^{d B}$. Since a closed form expression for $\operatorname{SINR}_{t h-l b}^{d B}$ cannot be obtained, $S I N R_{t h-l b}^{d B}$ has to be determined by solving equation (6) numerically. A closed form expression for $\operatorname{SINR}_{t h-l b}^{d B}$ can be obtained by adopting the following two approximations:

(i) $\quad \mathrm{N}$ is modeled as Gaussian random variable

(ii) $P_{\text {outN }}$ is approximated by a step function instead of the continuously-increasing function given in equation (2). 
International Journal of Wireless \& Mobile Networks (IJWMN) Vol. 3, No. 5, October 2011

Using these approximations, it can be shown that the closed form expression for $\operatorname{SINR}_{t h-l b}^{d B}$ is given as

$$
\operatorname{SINR}_{t h-l b}^{d B}=m+\sigma \varphi\left[\frac{\varphi^{2}\left(\frac{P_{o u t-\max }-\phi}{1-\phi}\right)+2 N_{t r}-\sqrt{\left(\varphi^{2}\left(\frac{P_{o u t-\max }-\phi}{1-\phi}\right)+2 N_{t r}\right)^{2}-4 N_{t r}^{2}}}{2 \Lambda}\right]
$$

where $N_{t r}$ is the transition value of the step function; $\varphi$ is the inverse Q-function such that

$$
y=Q(x) \Leftrightarrow x=\varphi(y), \text { and } \phi=P_{o u t \mid N<N \max } .
$$

and $\mathrm{Q}(\mathrm{x})$ is given by

$$
Q(x)=\frac{1}{\sqrt{2 \pi}} \int_{x}^{\infty} e^{-\frac{t^{2}}{2}}
$$

\section{INTERFACE DESIGN/SimULATION}

In this section, we present the simulation interface for data capture and processing. The input parameters for the simulation are as shown in Table 1 while the input form design is shown in Figure 1. The simulation program that drives both ends of the design (the interface and processing) is developed using the Java programming language.

Table 1. Model input parameters and values

\begin{tabular}{|l|l|}
\hline Parameter & Empirical value \\
\hline Minimum Signal-interference-noise ratio $\left(S I N R_{\text {min }}\right)$ & $18 \mathrm{~dB}$ \\
\hline Target signal-interference-noise ratio $\left(S I N R_{t r g}\right)=(m)$ & $12 \mathrm{~dB}$ \\
\hline Lower bound threshold SINR $\left(\right.$ SINR $\left._{t h-l b}\right)$ & $15.5 \mathrm{~dB}$ \\
\hline Adjustment Parameter $1(\varphi)$ & $Q^{-1}$ \\
\hline Adjustment Parameter $2(\phi)$ & 0.5 \\
\hline Transition value of the step function $N_{t r}$ & 40 \\
\hline Average traffic intensity in Erlang per cell $(\wedge)$ & $(5-30)$ Erlang/s \\
\hline Standard deviation of SINR $(\sigma)$ & 8 \\
\hline Function $(Q(x))$ & $\mathrm{Q}$ \\
\hline
\end{tabular}


International Journal of Wireless \& Mobile Networks (IJWMN) Vol. 3, No. 5, October 2011

The empirical data in Table 1 were gathered from an urban environment and fed as input to the simulation. The power outage data used for computing the Q-function were obtained from an established network operating in Nigeria (Airtel Nigeria). These data are presented in the Apendix.

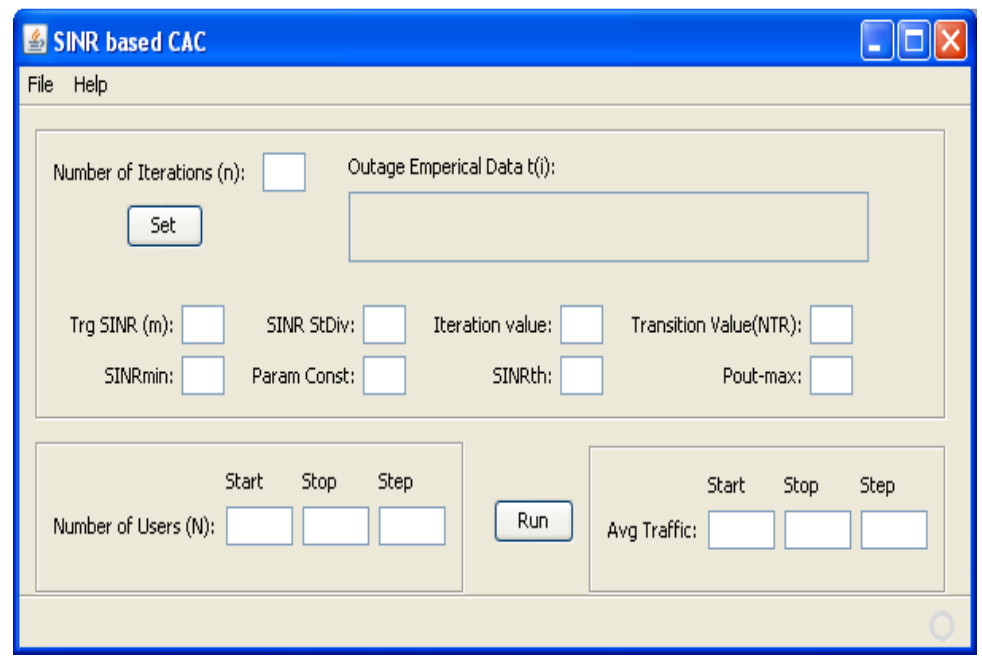

Figure 1. Simulation form design

The simulation interface is dynamic in nature and can be used as a design prototype for fine tuning the performance of other networks. Results obtained from the simulation are discussed in the next section.

\section{Simulation RESUlts}

Figure 2 is a graph of SINR vs. system load values (traffic). We observe from the graph that the SINR increases as the traffic intensity increases. This proves that our call admission control scheme is able to effectively control the accepted load and guarantee low dropping probability due to proper setting of the admission threshold. Also with our CAC algorithm, it is possible to tune the acceptance threshold in order to improve utilization of the network resources in a remarkable way. 
International Journal of Wireless \& Mobile Networks (IJWMN) Vol. 3, No. 5, October 2011

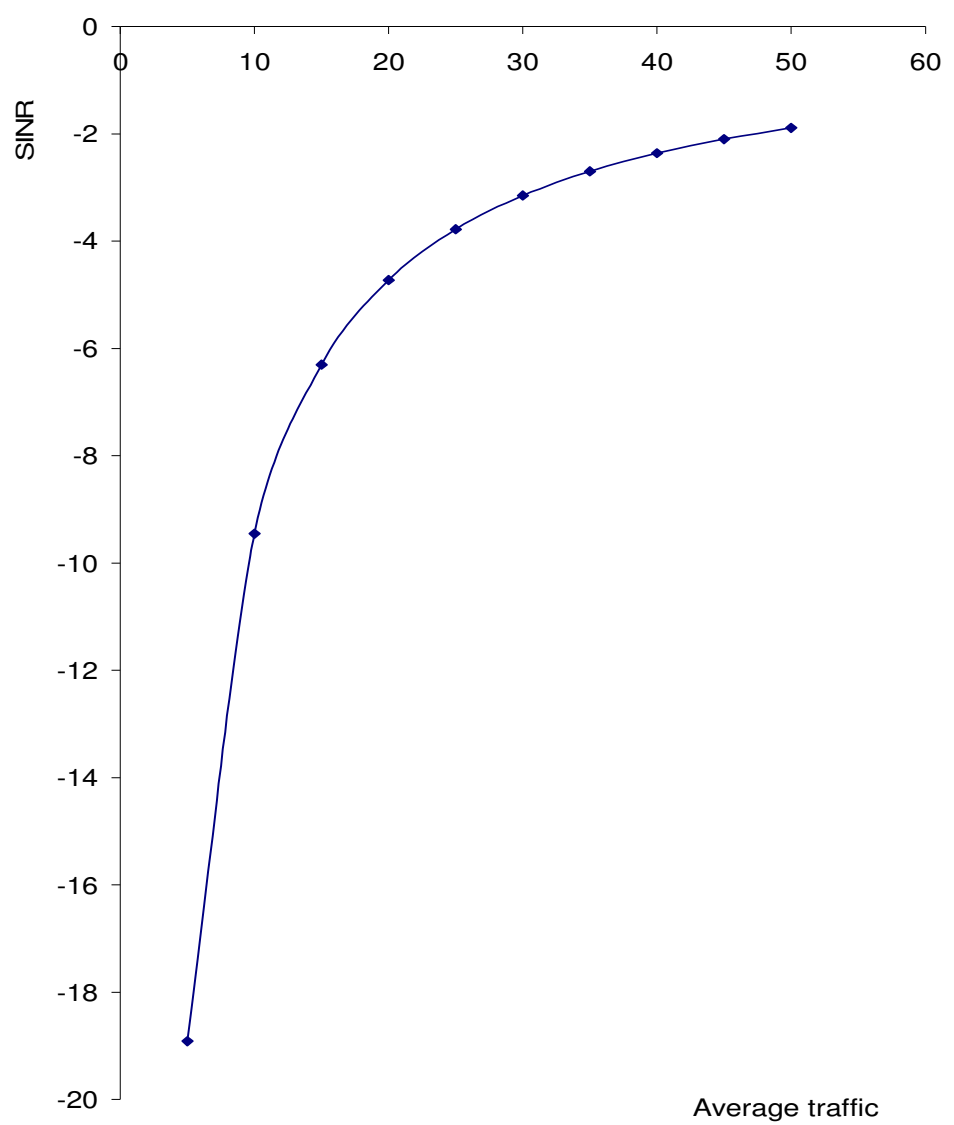

Figure 2. A graph of SINR vs. average traffic

Other results are the plots of call blocking vs. system load and call blocking vs. number of callers, shown in Figure 3 and Figure 4 respectively. We observe in Figure 3 that call blocking per cell increases as the system load increases; this is due to cell interference. When the number of users is higher, blocking is higher. This can jeopardize the system and consequently reduce the SINR (see Figure 4). 
International Journal of Wireless \& Mobile Networks (IJWMN) Vol. 3, No. 5, October 2011

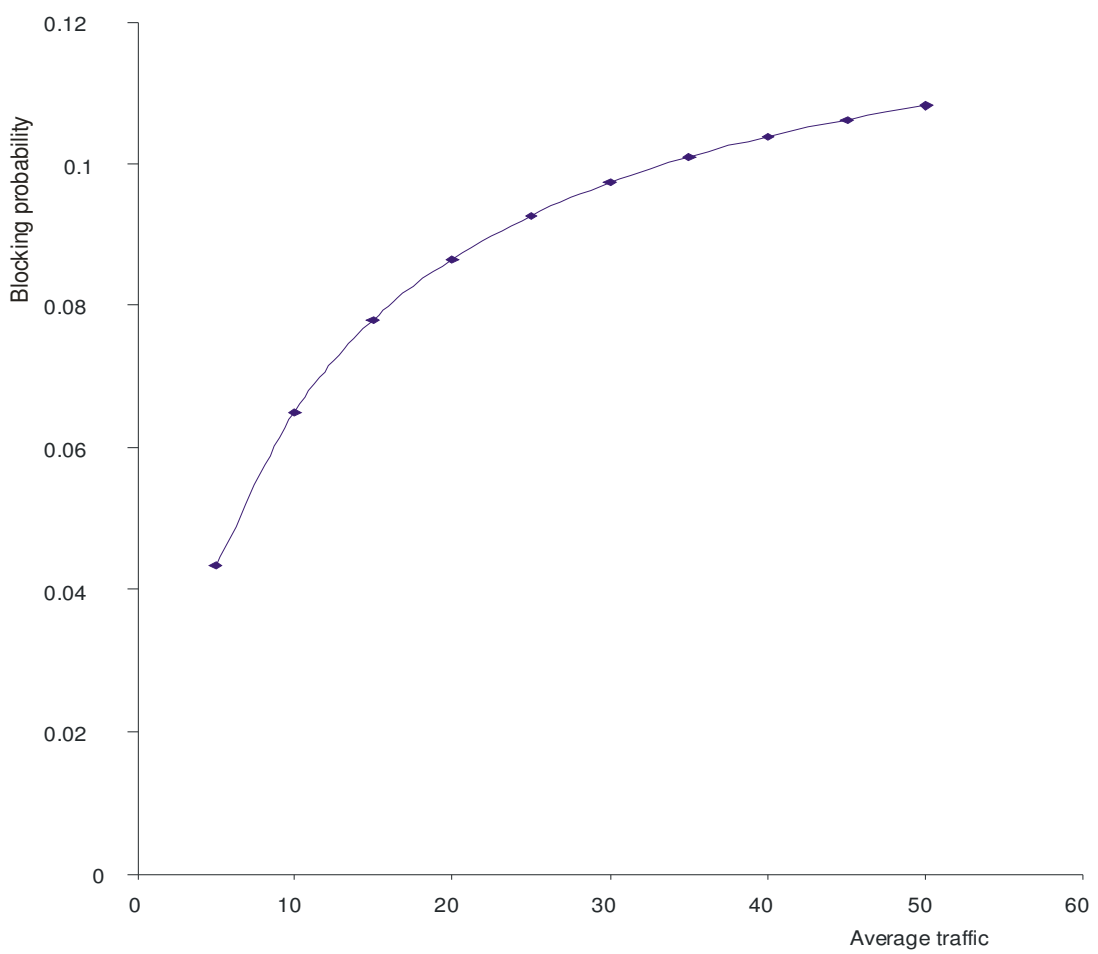

Figure 3. A graph of power outage vs. average traffic

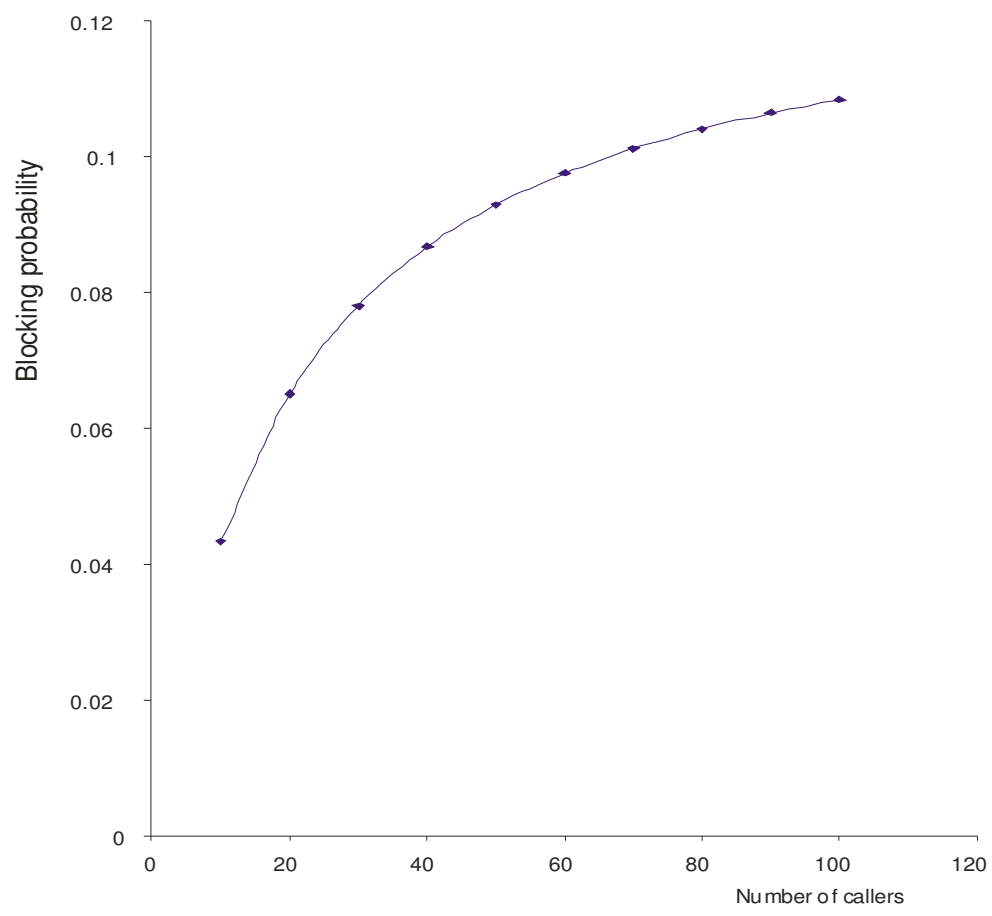

Figure 4. A graph of blocking vs. number of callers 
International Journal of Wireless \& Mobile Networks (IJWMN) Vol. 3, No. 5, October 2011

\section{Conclusions}

The concept of minimizing call blocking probability is an optimization technique that provides fair QoS to a set of users in the wireless network. There is also the need for an efficient call admission control strategy in the admission control mechanism to make the decision of accepting or rejecting calls, keeping the blocking probability minimal in a well known interference limited 3G- based CDMA network.

In this paper, an improved lower bound $\operatorname{SINR}_{t h}\left(\operatorname{SINR}_{t h-l b}\right)$ was derived and analyzed for CDMA under imperfect power control conditions by computing the probability of the users' capacity applying the law of total probability. We obtain $S I N R_{t h-l b}$ by establishing a relationship between $P_{b}$ and the lowest value of $S I N R_{t h}$ such that the blocking probability $\left(P_{b}\right)$ is kept below the corresponding maximum value $\left(P_{b-\max }\right)$. We assumed that calls blocking occur due to Power Control (PC) infeasibility, while SINR fluctuations occur due to imperfect power control. This proves that $S I N R_{t h-l b}$ is important for selecting an appropriate value of $S I N R_{t h}$. We have also demonstrated that $S I N R_{t h-l b}$ gives an indication of the system capacity computation taking into account the QoS constraints. The results show that our approach of determining the lower value of $S I N R_{t h-l b}$ to keep the blocking probability below the maximum value is vital for QoS improvement across CDMA networks.

\section{ACKNOWLEDGEMENTS}

The authors would like to thank the anonymous reviewers for their useful comments that have contributed to enhancing the quality of this paper, and also the staff of Airtel Nigeria for their assistance during data collection for this research.

\section{REFERENCES}

[1] Fang, Yuguang \& Zang, Yi, (2002). "Call Admission Control Schemes and Performance Analysis in Wireless Mobile Networks". IEEE Transactions on Vehicular Technology. Vol. 1, No. 2, pp. 371-382.

[2] Jeon, Sook. \& Jeong, Dong Geun, (2002). "Call Admission Control for CDMA Mobile Communications Systems Supporting Multimedia Services". IEEE Transactions on Wireless Communications. Vol. 1, No. 4, pp. 649-659.

[3] Pires, Gadec, (2006). Multi-cell Admission Control for WCDMA Networks. M.Sc. Thesis, School of Information and Communication Technology, Stockholm, Sweden.

[4] Holma, Harri. \& Toskala, Antti, (2002). WCDMA for UMTS. Second Edition, John Wiley and Sons Inc., New York.

[5] Ramjee, Ramachandran, Towsley, Don \& Nagarajan, (1997), "On Optimal call Admission Control in Cellular Networks" Wireless Networks, Vol. 3, No. 1, pp. 1-8.

[6] Bannister, Jeffery, Mather, Paul \& Coope, Sebastian, (2004). Convergence Technologies for $3 G$ Networks. John Wiley and Sons Ltd, New York. 
International Journal of Wireless \& Mobile Networks (IJWMN) Vol. 3, No. 5, October 2011

[7] Singh, Sumeetpal., Krishnamurthy Vikram \& Poor H. Vincent, (2002), "Integrated Voice/Data Call Admission Control for Wireless DS-CDMA Systems with Fading”, IEEE Transactions on Signal Processing. Vol. 50, pp. 1483-1495.

[8] Ramesh Babu. H.S., Gowrishankar, Gowrishankar \& Satyanarayana P.S, (2010). "Call Admission Control for Next Generation Wireless Networks using Higher Order Markov Model", Computer and Information Science, Vol. 3, No. 1., pp. 192-198.

[9] Liu, Zhao \& El-Zarki, Magda, (1994), "SIR-based Call Admission Control for DS-CDMA Cellular Systems", IEEE Journals on Selected Areas in Communication. Vol. 12, No. 4, pp. 638-644.

[10] Ahmed, Mohamed \& Yanikomeroglu, Halim, (2005), "SINR Threshold Lower Bound for SINR-based Call Admission Control in CDMA Networks with Imperfect Power Control”, IEEE Communications Letters, Vol. 9, No. 4, pp. 331-333.

[11] Kim, Dongwoo, (2002), “On Upper Bounds of SIR-based Call Admission Threshold in Power Controlled DS-CDMA Mobile Systems” IEEE Communications Letters. Vol. 6, No. 1, pp. 1315.

[12] El-Sayes Mohamed \& Ahmed, Mohamed H. (2007), An Upper Bound on SINR Threshold for Call Admission Control in Multiple-Class CDMA Systems with Imperfect Power-Control. In Proceedings of IEEE Vehicular Technology Conference-Spring (VTC'07-Spring), Dublin, Ireland, April 2007.

[13] Andrews, M and Dinitz, M. (2009). Maximizing Capacity in Arbitrary Wireless Networks in the SINR Model: Complexity and Game Theory. In Proceedings of IEEE INFOCOM '09, pp. 1332-1340.

[14] Chen, Yung-Han, Chang, Chung-Ju. \& Shen, Scott, (2001), An Outage-based Fuzzy Call Admission Control for WCDMA. In Proceedings of 12th IEEE International Symposium on Personal Indoor and Mobile Radio Communication (PIMRC'01). Vol. 1, pp. B-15-B-19.

[15] Ahmed, Mohamed .H. (2005). "Call Admission Control in Wireless Networks: A Comprehensive Survey”, IEEE Communications Surveys and Tutorials, Vol. 7, No. 1, pp. 5069.

[16] Chak Jean \& Zhuang Weihua, (2000). Capacity Analysis for Connection Admission Control for Indoor Multimedia Wireless Communications. Wireless Personal Communications, Vol. 12, pp. 269-282

[17] Carciofi C., Frullone M. and Missiroli M. (1999). Third Generation W-CDMA in Real Environments: Impact of Quality Adaptive Call Admission Policies on the Spatial Distribution of Blocking Probability. In Proceedings of ACTS Mobile Communications Summit'09.

[18] Casoni, M., Immovilli, G. and Merani, M. (2002), “Admission Control in T/CDMA Systems Supporting Voice and Data Applications", IEEE Transactions on Wireless Communication. Vol. 1, No. 3, pp. 540-548.

[19] Ayyagari, D. and Ephremides, A., (2003), "Optimal Admission Control in Cellular DS-CDMA Systems with Multimedia Traffic", IEEE Transactions on Wireless Communication, Vol. 2, No. 1, pp. 195-202.

[20] Shu, Tao \& Niu, Zhisheng, (2002), Call Admission Control using Differentiated Outage Probabilities in Multimedia DS-CDMA Networks with Imperfect Power Control. In Proceedings of 11th International Conference on Computer Communication and Networking, Oct. 2002, pp. 336-341. 
International Journal of Wireless \& Mobile Networks (IJWMN) Vol. 3, No. 5, October 2011

[21] Comaniciu, Cristina \& Poor, Vincent, H. (2003), "Jointly Optimal Power and Admission Control for Delay Sensitive Traffic in CDMA Networks with LMMSE Receivers", IEEE Transactions on Signal Processing. Vol. 51, No. 8, pp. 2031-2042.

[22] Nie Chun, Yong, Huat Chew \& Wong David Tung Chong, (2006), "Cross-Layer Quality-ofService Analysis and Call Admission Control in the Uplink of CDMA Cellular Networks". EURASIP Journal on Wireless Communications and Networking. Vol. 2006, pp. 1-14.

[23] Leon-Garcia, Alberto, (1994), Probability and Random Processes for Electrical Engineering, Second Edition. Addison-Wesley Inc.

\section{APPENDIX}

Empirical data of power outages in minutes obtained from various base stations of Airtel Nigeria

\begin{tabular}{|c|c|c|c|c|c|}
\hline $\begin{array}{l}\text { Outage in } \\
\text { mins }\end{array}$ & & & & & \\
\hline Vendor & BSC & Sept 3-09 & Sept 10-16 & Sept 17-23 & $\begin{array}{l}\text { Sept 24- } \\
30\end{array}$ \\
\hline MOTOROLA & MAKBS09 & 74.8642 & 0.1350 & 6.1350 & 92.1165 \\
\hline MOTOROLA & MAKBS11 & 0.0190 & 1.5804 & 42.2514 & 173.3755 \\
\hline MOTOROLA & MAKBS12 & 169.9470 & 111.4364 & 341.1228 & 267.9648 \\
\hline MOTOROLA & MAKBS16 & 93.2333 & 17.2597 & 273.3534 & 62.8771 \\
\hline MOTOROLA & MAKBS22 & 20.9720 & 1.5617 & 31.7144 & 40.2301 \\
\hline MOTOROLA & MAKBS40 & 1.3304 & 148.3167 & 244.8690 & 111.5961 \\
\hline Vendor & BSC & Oct 1-7 & Oct 8-14 & Oct 15-21 & $\begin{array}{l}\text { Oct 22- } \\
28\end{array}$ \\
\hline MOTOROLA & MAKBS09 & 10.6208 & 45.1356 & 151.0155 & 152.7242 \\
\hline MOTOROLA & MAKBS11 & 243.7435 & 307.2562 & 132.8703 & 91.8661 \\
\hline MOTOROLA & MAKBS12 & 20.0501 & 34.0964 & 155.0567 & 76.4463 \\
\hline MOTOROLA & MAKBS16 & 146.8725 & 117.8995 & 81.5078 & 73.8557 \\
\hline MOTOROLA & MAKBS22 & 9.6119 & 44.5952 & 146.4753 & 165.6607 \\
\hline MOTOROLA & MAKBS40 & 127.4351 & 81.4865 & 40.0305 & 109.5762 \\
\hline Vendor & BSC & Oct 29-Nov 4 & Nov 5-11 & Nov 12-18 & $\begin{array}{l}\text { Nov 19- } \\
25 \\
\end{array}$ \\
\hline MOTOROLA & MAKBS09 & 17.2500 & 117.4847 & 104.2976 & 103.7529 \\
\hline MOTOROLA & MAKBS11 & 287.7560 & 160.3098 & 170.4908 & 37.6577 \\
\hline MOTOROLA & MAKBS12 & 202.6322 & 209.1965 & 200.8598 & 13.4058 \\
\hline MOTOROLA & MAKBS16 & 263.4556 & 159.3320 & 63.8144 & 41.5822 \\
\hline MOTOROLA & MAKBS22 & 92.2691 & 50.5358 & 16.5602 & 14.8117 \\
\hline MOTOROLA & MAKBS40 & 116.2429 & 85.1428 & 46.1811 & 207.8068 \\
\hline
\end{tabular}


International Journal of Wireless \& Mobile Networks (IJWMN) Vol. 3, No. 5, October 2011

\begin{tabular}{|c|c|c|c|c|c|}
\hline Vendor & BSC & Nov 26-Dec 2 & & & \\
\hline MOTOROLA & MAKBS09 & 6.3524 & & & \\
\hline MOTOROLA & MAKBS11 & 129.5626 & & & \\
\hline MOTOROLA & MAKBS12 & 11.2581 & & & \\
\hline MOTOROLA & MAKBS16 & 76.2423 & & & \\
\hline MOTOROLA & MAKBS22 & 10.4821 & & & \\
\hline MOTOROLA & MAKBS40 & 71.2646 & & & \\
\hline$\%$ Outage & & & & & \\
\hline Vendor & BSC & Sept 3-09 & Sept 10-16 & Sept 17-23 & $\begin{array}{l}\text { Sept 24- } \\
30\end{array}$ \\
\hline MOTOROLA & MAKBS09 & 0.7427 & 0.0013 & 0.0609 & 0.9139 \\
\hline MOTOROLA & MAKBS11 & 0.0002 & 0.0157 & 0.4192 & 1.7200 \\
\hline MOTOROLA & MAKBS12 & 1.6860 & 1.1055 & 3.3842 & 2.6584 \\
\hline MOTOROLA & MAKBS16 & 0.9249 & 0.1712 & 2.7118 & 0.6238 \\
\hline MOTOROLA & MAKBS22 & 0.2081 & 0.0155 & 0.3146 & 0.3991 \\
\hline MOTOROLA & MAKBS40 & 0.0132 & 1.4714 & 2.4293 & 1.1071 \\
\hline Vendor & BSC & Oct 1-7 & Oct 8-14 & Oct 15-21 & Oct $22-28$ \\
\hline MOTOROLA & MAKBS09 & 0.1054 & 0.4478 & 1.4982 & 1.5151 \\
\hline MOTOROLA & MAKBS11 & 2.4181 & 3.0482 & 1.3182 & 0.9114 \\
\hline MOTOROLA & MAKBS12 & 0.1989 & 0.3383 & 1.5383 & 0.7584 \\
\hline MOTOROLA & MAKBS16 & 1.4571 & 1.1696 & 0.8086 & 0.7327 \\
\hline MOTOROLA & MAKBS22 & 0.0954 & 0.4424 & 1.4531 & 1.6435 \\
\hline MOTOROLA & MAKBS40 & 1.2642 & 0.8084 & 0.3971 & 1.0871 \\
\hline Vendor & BSC & Oct 29-Nov 4 & Nov 5-11 & Nov 12-18 & Nov 19-25 \\
\hline MOTOROLA & MAKBS09 & 0.1711 & 1.1655 & 1.0347 & 1.0293 \\
\hline MOTOROLA & MAKBS11 & 2.8547 & 1.5904 & 1.6914 & 0.3736 \\
\hline MOTOROLA & MAKBS12 & 2.0102 & 2.0754 & 1.9927 & 0.1330 \\
\hline MOTOROLA & MAKBS16 & 2.6136 & 1.5807 & 0.6331 & 0.4125 \\
\hline MOTOROLA & MAKBS22 & 0.9154 & 0.5013 & 0.1643 & 0.1469 \\
\hline MOTOROLA & MAKBS40 & 1.1532 & 0.8447 & 0.4581 & 2.0616 \\
\hline Vendor & BSC & Nov 26-Dec 2 & & & \\
\hline MOTOROLA & MAKBS09 & 0.0630 & & & \\
\hline MOTOROLA & MAKBS11 & 1.2853 & & & \\
\hline MOTOROLA & MAKBS12 & 0.1117 & & & \\
\hline MOTOROLA & MAKBS16 & 0.7564 & & & \\
\hline MOTOROLA & MAKBS22 & 0.1040 & & & \\
\hline
\end{tabular}


International Journal of Wireless \& Mobile Networks (IJWMN) Vol. 3, No. 5, October 2011

\begin{tabular}{|c|c|c|c|c|c|}
\hline MOTOROLA & MAKBS40 & 0.7070 & & & \\
\hline \multicolumn{6}{|c|}{$\%$ Network Availability } \\
\hline Vendor & BSC & Sept 3-09 & Sept 10-16 & Sept 17-23 & $\begin{array}{l}\text { Sept 24- } \\
30\end{array}$ \\
\hline MOTOROLA & MAKBS09 & 99.2573 & 99.9987 & 99.9391 & 99.0861 \\
\hline MOTOROLA & MAKBS11 & 99.9998 & 99.9843 & 99.5808 & 98.2800 \\
\hline MOTOROLA & MAKBS12 & 98.3140 & 98.8945 & 96.6158 & 97.3416 \\
\hline MOTOROLA & MAKBS16 & 99.0751 & 99.8288 & 97.2882 & 99.3762 \\
\hline MOTOROLA & MAKBS22 & 99.7919 & 99.9845 & 99.6854 & 99.6009 \\
\hline MOTOROLA & MAKBS40 & 99.9868 & 98.5286 & 97.5707 & 98.8929 \\
\hline Vendor & BSC & Oct 1-7 & Oct 8-14 & Oct 15-21 & Oct 22-28 \\
\hline MOTOROLA & MAKBS09 & 99.8946 & 99.5522 & 98.5018 & 98.4849 \\
\hline MOTOROLA & MAKBS11 & 97.5819 & 96.9518 & 98.6818 & 99.0886 \\
\hline MOTOROLA & MAKBS12 & 99.8011 & 99.6617 & 98.4617 & 99.2416 \\
\hline MOTOROLA & MAKBS16 & 98.5429 & 98.8304 & 99.1914 & 99.2673 \\
\hline MOTOROLA & MAKBS22 & 99.9046 & 99.5576 & 98.5469 & 98.3565 \\
\hline MOTOROLA & MAKBS40 & 98.7358 & 99.1916 & 99.6029 & 98.9129 \\
\hline Vendor & BSC & Oct 29-Nov 4 & Nov 5-11 & Nov 12-18 & Nov $19-25$ \\
\hline MOTOROLA & MAKBS09 & 99.8289 & 98.8345 & 98.9653 & 98.9707 \\
\hline MOTOROLA & MAKBS11 & 97.1453 & 98.4096 & 98.3086 & 99.6264 \\
\hline MOTOROLA & MAKBS12 & 97.9898 & 97.9246 & 98.0073 & 99.8670 \\
\hline MOTOROLA & MAKBS16 & 97.3864 & 98.4193 & 99.3669 & 99.5875 \\
\hline MOTOROLA & MAKBS22 & 99.0846 & 99.4987 & 99.8357 & 99.8531 \\
\hline MOTOROLA & MAKBS40 & 98.8468 & 99.1553 & 99.5419 & 97.9384 \\
\hline Vendor & BSC & Nov 26-Dec 2 & & & \\
\hline MOTOROLA & MAKBS09 & 99.9370 & & & \\
\hline MOTOROLA & MAKBS11 & 98.7147 & & & \\
\hline MOTOROLA & MAKBS12 & 99.8883 & & & \\
\hline MOTOROLA & MAKBS16 & 99.2436 & & & \\
\hline MOTOROLA & MAKBS22 & 99.8960 & & & \\
\hline MOTOROLA & MAKBS40 & 99.2930 & & & \\
\hline
\end{tabular}


International Journal of Wireless \& Mobile Networks (IJWMN) Vol. 3, No. 5, October 2011

\section{Authors}

Moses Ekpenyong is an Academic staff of the Department of Computer Science, University of Uyo, Nigeria, and has B.Sc., M.Sc., Computer Science. His Ph.D. research is in Speech Technology. He belongs to the following professional bodies: Nigerian Association of Mathematical Physics (NAMP), Nigeria Computer Society (NCS), International Speech and Communications Association (ISCA), Nigeria Mathematical Society (NMS), Nigerian Statistical Association (NSA) and West-African Linguistics Society (WALS). He is an international scholar and has examined both undergraduate and postgraduate Thesis within and outside Nigeria. He has also enjoyed fruitful collaborations with colleagues at local and international levels and has published widely in his area of specialty: speech and wireless communications technology.

Joseph Isabona has B.Sc., Theoreti-cal Physics and M.Sc., Physics (Electronics/Communi $\neg$ cations), and is currently pursuing a $\mathrm{PhD}$ degree in Physics Electronics/Telecommunications. He lectures in the Department of Basic Sciences at Benson Idahosa University, Nigeria. He is a member of the Nigerian Association of Math $\neg$ ematical Physics (NAMP) and the Nigerian Institute of Physics (NIP). He has published both naᄀtionally and internationally in the area of wireless communications. His area of specialization is signal processing and radio resource management in wire $\neg$ less communication network
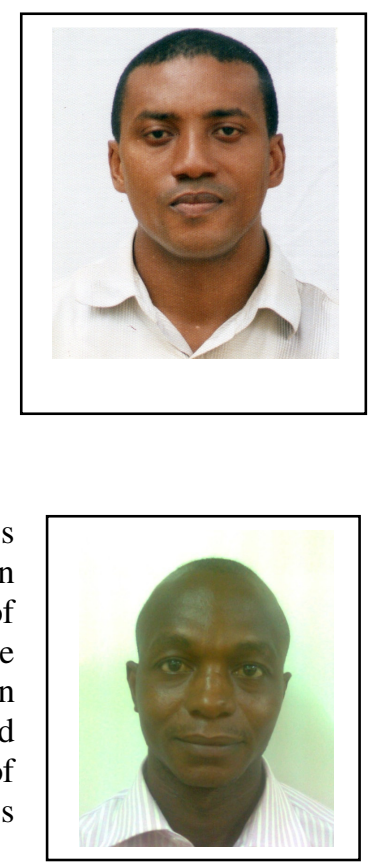